\title{
Social support network and quality of life in multiple sclerosis patients
}

\author{
Rede de apoio social e qualidade de vida de pacientes com esclerose múltipla \\ David Castro Costa1 ${ }^{1}$ Maria José Sá1,2, José Manuel Calheiros ${ }^{3}$
}

\begin{abstract}
Objective: To analyse the relationship between the social support network (SSN) and health related quality of life (HRQOL) in multiple sclerosis (MS) patients. Methods: The sample comprised 150 consecutive MS patients attending our MS clinic. To assess the socio-demographic data, a specifically designed questionnaire was applied. The HRQOL dimensions were measured with the Short-Form Health Survey Questionnaire-SF36 and the SSN with the Medical Outcomes Study Social Support Survey. Spearman's correlation was used to compare the magnitude of the relationship between the SSN and HRQOL. Results: The mean patient age was 41.7 years ( \pm 10.4 ; range: $18-70 \mathrm{yr}$ ); the mean Expanded Disability Status Score was 2.5 ( \pm 2.4 ; range: $0-9)$. There was a statistically significant correlation between the structure of the SSN and the HRQOL. Conclusion: The composition of the SSN, social group membership and participation in voluntary work have an important role in the HRQOL of patients with MS.
\end{abstract}

Keywords: multiple sclerosis; social networking; quality of life.

\section{RESUMO}

Objetivo: Analisar a relação entre a rede de apoio social (RAS) e a qualidade de vida relacionada com a saúde (QVRS) em pacientes com esclerose múltipla (EM). Métodos: Foram avaliados consecutivamente 150 pacientes na consulta de esclerose múltipla. As dimensões da QVRS foram medidas com Short-Form Health Survey Questionnaire-SF36 e a RAS com o Medical Outcomes Study Social Support Survey. A correlação de Spearman foi utilizada para comparar a magnitude da relação entre a RAS e a QVRS. Resultados: A idade média dos pacientes foi 41,7 anos ( \pm 10,4; intervalo: 18-70 anos); a média da EDSS foi 2,5 ( \pm 2,4; intervalo: 0-9). Foi encontrada uma correlação estatisticamente significativa entre a estrutura da RAS e a QVRS. Conclusão: A composição da RAS, a pertença a um grupo social e a participação em trabalho voluntário têm um papel importante na QVRS dos pacientes com MS.

Palavras-chave: esclerose múltipla; rede social; qualidade de vida.

Multiple sclerosis (MS) is a chronic illness of the central nervous system that affects the physical ${ }^{1}$, psychological $^{2}$ and social function ${ }^{3}$ of patients. These disturbances have a negative impact in the daily life activities and the quality of life of patients who are socially disadvantaged ${ }^{4}$, because they often lose their jobs, economic and social status, friends and family ${ }^{5,6,7}$.

In the last two decades, drug therapies that modify the MS natural history ${ }^{8,9}$, and the development of physical and psychological rehabilitation techniques ${ }^{10}$, have represented major contributions to improving the quality of life of patients and promoting their adaptation to the illness ${ }^{11}$. However, as those therapies are not curative and MS is a progressive disease, the importance of social support in the long term must be highlighted. In this field, several studies have shown that social support is an important positive factor in the health related quality of life (HRQOL) of patients with MS and may decrease their depressive symptoms ${ }^{3,12,13,14,15,16}$.

Conceptually, social support is a function of the social network that represents the social relationships with which each person interacts, maintains contact or some form of sharing. ${ }^{3}$. These concepts are frequently described as equivalent, but, in fact, they are different and have a distinct practical expression ${ }^{17}$. In practice, the social network is made up of all people with whom contact is maintained, which includes the frequency, the social ties, involvement in religious groups, voluntary associations and other groups ${ }^{18}$.

The social support network (SSN) is a subset of the social network, in which people are linked by social roles and

${ }^{1}$ Centro Hospitalar São João, Departamento de Neurologia, Porto, Portugal;

Universidade Fernando Pessoa, Faculdade de Ciências da Saúde, Porto, Portugal;

${ }^{3}$ Universidade Beira Interior, Faculdade de Ciências da Saúde, Covilhã, Portugal.

Correspondence: David Castro Costa; Centro Hospitalar São João; Alameda Prof. Hernâni Monteiro, 4200-319; Porto, Portugal; E-mail: dcac.costa@gmail.com Conflict of interest: There is no conflict of interest to declare.

Received 09 January 2016; Received in final form 07 November 2016; Accepted 03 February 2017. 
relationships, whose functions are the exchange of emotional support, financial assistance, guidance and advice in a variety of situations, particularly when someone is sick ${ }^{19}$. The SSN may be measured by composition, size and participation in sports groups, social meetings and voluntary work. Sociological studies conducted in Portugal have shown that different types of social support is provided by the SSN, specifically, by close family members ${ }^{20}$. This evidence revealed that the structure of the SSN seems to influence the social support that is provided.

Research about the relationship between the SSN and HRQOL show that participation in supporting groups is strongly linked to the decrease of anxiety and to satisfaction with life $^{21}$. Other studies about HRQOL with chronic patients have revealed that the patients' SSN is less than the SSN of healthy people ${ }^{19,22}$. The size of the SSN is less important for a patient than the ties between people. For patients with Hodgkin's lymphoma, the composition of the SSN, for example, friends or close family, is associated with a better HRQOL $^{23}$. However, there are no studies on the association between the SSN of MS patients and their HRQOL.

All these aspects are the major reason for the aim of this study, which analyzed the relationship between the SSN of patients with MS and their HRQOL.

\section{METHODS}

\section{Patients}

The sample included 150 adult patients with the diagnosis of MS according to the McDonald criteria ${ }^{24}$, consecutively evaluated at the Multiple Sclerosis Outpatient Clinic of Hospital S. João, Porto, who gave their informed consent. Illiterate patients were excluded, as well as those with physical and mental disabilities prior to the onset of disease. The Ethics Committee of Hospital S. João approved the study.

\section{Methods}

Clinical data about the MS history, such as duration, clinical course and disability assessed by the Expanded Disability Status Score (EDSS), were collected from medical records ${ }^{25}$.

Demographic data (age, gender, marital status, education level, profession) and the evaluation of the social support network and quality of life were obtained in an interview using a questionnaire specifically designed for this study.

\section{Instruments}

1) The EDSS results obtained after rating in the different Kurtzke functional systems is the most widely-used scale for assessing the disability of patients with MS. It is an ordinal scale with a range of values from 0 corresponding with a normal neurological examination, and 10 with death due to MS. It shows increments of 0.5 between units except between 0 and 1. A mild disability is determined by scores from $0-3.5$, moderate disability scores by between $4.0-6.0$, and severe disability by scores greater than or equal to $6.5^{25}$.

2) The Medical Outcomes Study Social Support Survey was used to assess the social support network. This scale was created and tested in a study of 2,987 adult users of health services in Boston, Chicago and Los Angeles, who had at least one of the following chronic diseases: hypertension, diabetes, coronary heart disease or depression ${ }^{26}$. The scale was translated and validated for the Portuguese language by Griep et al. ${ }^{18}$ The Medical Outcomes Study Social Support Survey comprises two subscales, one to assess the SSN and another to assess social support. The SSN subscale has five questions about composition, size and social contact frequency.

3) The HRQOL was assessed using the Health Status Questionnaire (SF-36v2) Portuguese version of the Medical Outcome Study 36-Item Health Survey Short Form (SF-36) ${ }^{27}$. It is an evaluation scale to assess HRQOL, adapted and validated for the Portuguese population, that measures eight dimensions of HRQOL based on the multidimensional model of health that is divided into two main components - physical and mental. The assessment of each item is made by using the method of points scored with values ranging from 0 to 100, where higher scores indicate a better quality of life. The scores of the fields are derived from the scores of items of that field and the scores of physical and mental components are derived from the fields associated with them.

\section{Statistical analysis}

We used the Statistical Package for the Social Sciences SPSS ${ }^{\bullet}$ for Windows, version 20.0 computer program to perform the statistical analysis.

To analyze the magnitude of the relationship between SSN and HRQOL, Spearman's correlation was used.

\section{RESULTS}

The social and clinical characteristics of the sample are shown in Table 1.

The mean age of patients was 41.7 years and the ratio women:men was 2:4.

Most patients were married $(66.0 \%)$, had a lower secondary education $(12.7 \% ; 38.7 \%)$ and unskilled occupations $(52.7 \%)$.The clinical parameters indicated that the form of relapsing-remitting MS was the most common (85.3\%), the mean duration of MS was 9.1 years $(6.4 ; 1-25)$ and the disability score $(68.7 \%)$ was low.

The composition of the SSN is shown in Table 2.

This composition consisted mostly of one to three relatives $(28.7 \%$; $24.7 \%$; $16.7 \%)$. However $10.0 \%$ of patients said they did not have a family member with whom they could talk to about almost everything. 
Table 1. Sample description (social characteristics and disease parameters).

\begin{tabular}{|c|c|c|c|}
\hline Variables & $n$ & $\%$ & M ( \pm Dp:Range) \\
\hline Age (years) & 150 & - & $41.7(10.5 ; 18-70)$ \\
\hline \multicolumn{4}{|l|}{ Sex } \\
\hline Female & 106 & 70.7 & - \\
\hline Male & 44 & 29.3 & - \\
\hline \multicolumn{4}{|l|}{ Marital status } \\
\hline Married & 99 & 66.0 & - \\
\hline Single & 25 & 16.7 & - \\
\hline Widow & 9 & 6.0 & - \\
\hline Divorced or separated & 17 & 11.3 & - \\
\hline \multicolumn{4}{|l|}{ School level } \\
\hline Inferior to primary education & 19 & 12.7 & - \\
\hline Completed primary education & 58 & 38.7 & - \\
\hline Completed secondary education & 48 & 32.0 & - \\
\hline Completed higher education & 25 & 16.7 & - \\
\hline \multicolumn{4}{|l|}{ Profession } \\
\hline Skilled workers & 71 & 47.3 & - \\
\hline Unskilled workers & 79 & 52.7 & - \\
\hline \multicolumn{4}{|l|}{ Clinical course of MS } \\
\hline Relapsing-remitting & 128 & 85.3 & - \\
\hline Primary progressive & 6 & 4.0 & - \\
\hline Secundary progressive & 16 & 10.7 & - \\
\hline MS Duration (years) & 150 & - & $9.1(6.4 ; 1-25)$ \\
\hline \multicolumn{4}{|l|}{ Disability } \\
\hline Low & 103 & 68.7 & - \\
\hline Moderate & 29 & 19.3 & - \\
\hline Severe & 18 & 12.0 & - \\
\hline EDSS & 150 & & $2.5(2.4: 0-9)$ \\
\hline
\end{tabular}

MS: multiple sclerosis; EDSS: expanded disability status scale

Concerning friends, $21.3 \%$ said they could not trust them. But on the other hand, most said they could count on one or more friends to talk to about everything $(74.75 \%)$.

Most patients did not participate in sports groups (73.3\%), meetings $(78.7 \%)$ or in voluntary work (84.75\%).

The relationship between the SSN and HRQOL is shown in Table 3.

A statistically significant correlation between the number of relatives, number of friends, participation in sports groups, participation in meetings, participation in volunteer work and the mental dimension of the HRQOL was found. The same correlation was observed for the physical dimension except for the question about the number of friends the patients could count on to talk to about almost everything.

\section{DISCUSSION}

The literature review showed that there are few studies on the association between the SSN and HRQOL of chronic patients ${ }^{17,19,22}$.

Moreover, there are no known studies about this field in MS patients. However, some studies have shown that
Table 2. Social support network

\begin{tabular}{|c|c|c|}
\hline Questions & $\mathrm{n}$ & $\%$ \\
\hline \multicolumn{3}{|c|}{ How many relatives can you trust to talk to about almost anything? } \\
\hline No relative & 15 & 10.0 \\
\hline One relative & 43 & 28.7 \\
\hline Two relatives & 37 & 24.7 \\
\hline Three relatives & 25 & 16.7 \\
\hline Four relatives & 12 & 8.0 \\
\hline Five relatives & 6 & 4.0 \\
\hline Six relatives & 7 & 4.7 \\
\hline Seven relatives & 4 & 2.7 \\
\hline Eight relatives & 1 & 0.7 \\
\hline \multicolumn{3}{|c|}{ How many friends can you trust to talk to about almost anything? } \\
\hline No friends & 38 & 25.3 \\
\hline One friend & 32 & 21.3 \\
\hline Two friends & 28 & 18.7 \\
\hline Three friends & 16 & 10.7 \\
\hline Four friends & 17 & 11.3 \\
\hline Five friends & 9 & 6.0 \\
\hline Six friends & 5 & 3.3 \\
\hline Seven friends & 2 & 1.3 \\
\hline Eight friends & 1 & 0.7 \\
\hline Ten friends & 2 & 1.3 \\
\hline \multicolumn{3}{|c|}{ Have you participated in sports in a group in the last 12 months? } \\
\hline No & 110 & 73.3 \\
\hline More than once per week & 13 & 8,7 \\
\hline Once a week & 2 & 1.3 \\
\hline Two or three times per week & 18 & 12.0 \\
\hline Few times a year & 7 & 4.7 \\
\hline Once a year & 0 & 0.0 \\
\hline \multicolumn{3}{|c|}{ Have you participated in meetings in the last 12 months? } \\
\hline No & 118 & 78.7 \\
\hline More than once per week & 12 & 8.0 \\
\hline Once a week & 5 & 3.3 \\
\hline Two or three times per week & 10 & 6.7 \\
\hline Few times a year & 0 & 0 \\
\hline Once a year & 5 & 3.3 \\
\hline \multicolumn{3}{|c|}{ Have you participated in voluntary work in the last 12 months? } \\
\hline No & 127 & 84.7 \\
\hline More than once per week & 14 & 9.3 \\
\hline Once a week & 2 & 1.3 \\
\hline Two or three times per week & 1 & 0.7 \\
\hline Few times a year & 5 & 3.3 \\
\hline Once a year & 1 & 0.7 \\
\hline
\end{tabular}

participation in supporting groups for patients with MS was strongly linked to decreased anxiety and increased satisfaction with life ${ }^{21}$, and supporting a person with MS had an impact on the lives of informal caregivers ${ }^{28}$.

One explanation for the low frequency of this type of analysis may be linked to the fact that the concept of a SSN is poorly defined, due to the heterogeneity in the analysis of its dimensions held by investigators, and it sometimes is confused with other close concepts, such as social support ${ }^{17,29}$. This theoretical obstacle requires the construction of network measurement scales of social support, systematizing 
Table 3. Correlation analysis: Relationship between SSN and HRQOL.

\begin{tabular}{|c|c|c|}
\hline Social support network & $\begin{array}{c}\text { HRQOL } \\
\text { Physical } \\
\text { health }\end{array}$ & $\begin{array}{l}\text { HRQOL } \\
\text { Mental } \\
\text { health }\end{array}$ \\
\hline \multicolumn{3}{|c|}{ How many relatives can you trust to talk to about almost anything? } \\
\hline Correlation coefficient & $0.227^{\star \star}$ & $0.302^{\star \star}$ \\
\hline Sig. (2-tailed); p-value & 0.005 & 0.000 \\
\hline n & 150 & 150 \\
\hline \multicolumn{3}{|c|}{ How many friends can you trust to talk to about almost anything? } \\
\hline Correlation coefficient & 0.159 & $0.208^{*}$ \\
\hline Sig. (2-tailed); p-value & 0.051 & 0.011 \\
\hline $\mathrm{n}$ & 150 & 150 \\
\hline \multicolumn{3}{|c|}{ Have you participated in sports in a group in the last 12 months? } \\
\hline Correlation coefficient & $0.283^{\star *}$ & $0.221^{\star *}$ \\
\hline Sig. (2-tailed); p-value & 0.000 & 0.007 \\
\hline n & 150 & 150 \\
\hline \multicolumn{3}{|c|}{ Have you participated in meetings in the last 12 months? } \\
\hline Correlation coefficient & $0.280^{\star \star}$ & $0.269^{* \star}$ \\
\hline Sig. (2-tailed); p-value & 0.001 & 0.001 \\
\hline $\mathrm{n}$ & 150 & 150 \\
\hline \multicolumn{3}{|c|}{ Have you participated in voluntary work in the last 12 months? } \\
\hline Correlation coefficient & $0.245^{\star \star}$ & $0.247^{* \star}$ \\
\hline Sig. (2-tailed); p-value & 0.003 & 0.002 \\
\hline n & 150 & 150 \\
\hline
\end{tabular}

*Correlation is significant at the 0.05 level (2-tailed); ${ }^{*}$ Correlation is significant at the 0.01 level (2-tailed). HRQOL: health related quality of life; SSN: Social Support Network.

the way of measuring all its dimensions. However, there is consensus that the SSN should be assessed in its composition, size, frequency of contact, and duration.

The composition may include family, neighbors and community organizations. The size refers to the number of people present in the network. The assessment of the SSN may capture the frequency of contacts between the number of people present and the duration of such contacts.

The analyzed literature used different scales to assess the SSN: The Arizona Social Support Interview Survey ${ }^{22}$, the Norbeck Social Support Questionnaire ${ }^{19}$ and the Convoy of Social Support ${ }^{17}$. These studies were cross-sectional types ${ }^{17,19}$ or descriptive approaches ${ }^{22}$ with 224,69 and 14 participants, respectively.

In this study, we used the Medical Outcomes Study Social Support Survey because it is adapted to the Portuguese language and was used in the measurement of the SSN.

Considering the lack of studies on the relationship between the SSN and the HRQOL of patients with MS, we compared the results of studies with other chronic patients.

The social characteristics of patients described in the literature showed different results among them. However, we observed that patients with spinal cord injury ${ }^{22}$ had a mean age of 47.5 years and 59.4 years for cancer patients ${ }^{17}$. These ages are characteristics of a productive period of life. These mean ages are close to the ages of patients of this study (Table 1), which is younger than the patients of the other samples analyzed.

The patients were mainly married (66.0\%) and female (70.7\%). Most had middle socioeconomic status, whichincluded education
(38.7\%), and occupation (52.7\%). No study presented an assessment of the physical disability of patients in order to compare this with MS patients (EDSS mean = 2.5; 2.4: 0 -9).

With regard to the size of the SSN (Table 2), the majority of MS patients reported that they had only one available person to help (relative $28.7 \%$; friends $21.3 \%$ ), two or three family members $(24.7 \% ; 16.7 \%)$ or friends $(18.7 \% ; 10.7 \%)$ to help. This result is in line with the results of the reviewed studies, showing that the SSN is made up of family members and people that patients consider as friends, which indicates that the size associated with the type of bond has a positive effect in the social support for patients ${ }^{3,17,19}$.

However, the relationship of other SSN dimensions (size, type of participants, contact frequency) with the HRQOL of patients is not known. The analyzed studies concluded that there was a statistically significant relationship between the SSN and HRQOL, or that the SSN was associated with better HRQOL in the patients studied, ${ }^{23}$ which was a source of the social support structure ${ }^{19,22}$ and group membership was strongly linked to life satisfaction ${ }^{21}$. These results are in accordance with the data from our study (Table 3) that showed statistically significant positive correlations between the SSN composition, social group membership, participation in voluntary work, engaging in sports activities in a group and the HRQOL (physical health and mental health dimensions). The fact that someone has friends is correlated with the psychological dimension, but not with the physical dimension, of the HRQOL.

Unlike other studies, we used the Medical Outcomes Study Social Support Survey because it also evaluates the levels of patient participation in sporting activities in groups, attending meetings and participating in volunteer work. In this study, the frequency of participation was low, because the majority of patients reported they had not participated in activities in recent months, despite the levels of disability of the disease being minimal. It can be assumed that MS is not a disease that affects this kind of participation, which seems to be the result of an SSN being centered in family and friends, and not in other social groups. However, despite the low participation in the aforementioned social groups, this was correlated with the HRQOL, which gives it a significant influence in this relationship.

In conclusion, social support network composition, social group membership, taking part in group sports and participation in voluntary work, have an important role in the HRQOL of patients with MS.

It is the SSN that provides the essential social support for the patient's adaptation to the daily living circumstances related to the disease.

The specialist working with MS needs to look at the individual patient and respective SSN as important elements of adaptation to illness and HRQOL, and encourage patients to participate in different social groups.

In practice, this study highlights the importance of a multidisciplinary team in repairing the SSN that is often affected by the loss of social functions in MS patients. 


\section{References}

1. Tortorella P, Lagana MM, Saresella M, Tavazzi E, Preti MG, Ricci $C$ et al. Determinants of disability in multiple sclerosis: an immunological and MRI study. BioMed Res Int. 2014;2014:ID875768. https://doi.org/10.1155/2014/875768

2. Tesar N, Baumhackl U, Kopp M, Günther V. Effects of psychological group therapy in patients with multiple sclerosis. Acta Neurol Scand. 2003;107(6):394-9. https://doi.org/10.1034/j.1600-0404.2003.00077.x

3. Costa DC, Sá MJ, Calheiros JM. The effect of social support on the quality of life of patients with multiple sclerosis. Arq Neuropsiquiatr. 2012;70(2):108-13. https://doi.org/10.1590/S0004-282X2012000200007

4. McCabew MP, De Judicibus M. The effects of economic disadvantage on psychological well-being and quality of life among people with multiple sclerosis.J Health Psychol. 2005;10(1):163-73. https://doi.org/10.1177/1359105305048562

5. Costa DC, Sá MJAM, Calheiros JM. Social characteristics and quality of life of multiple sclerosis Portuguese patients. Neurol Ther. 2013;2(1):43-56. https://doi.org/10.1007/s40120-013-0011-4

6. Pack TG, Szirony GM, Kushner JD, Bellaw JR. Quality of life and employment in persons with multiple sclerosis. Work. 2014;49(2):281-7. https://doi.org/10.3233/WOR-131711

7. Moore P, Harding KE, Clarkson H, Pickersgill TP, Wardle M, Robertson NP. Demographic and clinical factors associated with changes in employment in multiple sclerosis. Mult Scler. 2013;19(12):1647-54. https://doi.org/10.1177/1352458513481396

8. Aljumah M, Alroughani R, Alsharoqi I, Bohlega SA, Dahdaleh M, Deleu $D$ et al. Future of management of multiple sclerosis in the middle East: a consensus view from specialists in ten countries. Mult Scler Int. 2013;2013:ID952321. https://doi.org/10.1155/2013/952321

9. Garnock-Jones KP. Alemtuzumab: a review of its use in patients with relapsing multiple sclerosis. Drugs. 2014;74(4):489-504. https://doi.org/10.1007/s40265-014-0195-7

10. Sá MJ. Exercise therapy and multiple sclerosis: a systematic review. J Neurol. 2014;261(9):1651-61. https://doi.org/10.1007/s00415-013-7183-9

11. Ploughman M, Austin MW, Murdoch M, Kearney A, Godwin M, Stefanelli M. The path to self-management: a qualitative study involving older people with multiple sclerosis. Physiother Can. 2012;64(1):6-17. https://doi.org/10.3138/ptc.2010-42

12. Cosio D, Jin L, Siddique J, Mohr DC. The effect of telephone-administered cognitive-behavioral therapy on quality of life among patients with multiple sclerosis. Ann Behav Med. 2011;41(2):227-34. https://doi.org/10.1007/s12160-010-9236-y

13. Costa D, Sá MJ, Calheiros JM. [The effect of social support on the symptoms of depression experienced by Portuguese patients with multiple sclerosis]. Rev Neurol. 2011;53(8):457-62. Spanish.

14. Kohlmann T, Wang C, Lipinski J, Hadker N, Caffrey E, Epstein $\mathrm{M}$ et al. The impact of a patient support program for multiple sclerosis on patient satisfaction and subjective health status. J Neurosci Nurs. 2013;45(3):E3-14. https://doi.org/10.1097/JNN.0b013e31828a4161

15. Finlayson ML, Cho CC. A profile of support group use and need among middle-aged and older adults with multiple sclerosis. J Gerontol Soc Work. 2011;54(5):475-93. https://doi.org/10.1080/01634372.2011.575446

16. Schwartz C, Frohner R. Contribution of demographic, medical, and social support variables in predicting the mental health dimension of quality of life among people with multiple sclerosis. Health Soc Work. 2005;30(3):203-12. https://doi.org/10.1093/hsw/30.3.203

17. Rodrigues JS, Ferreira NM. Estrutura e funcionalidade da rede de apoio social do adulto com câncer. Acta Paul Enferm. 2012;25(5):781-7. https://doi.org/10.1590/S0103-21002012000500021

18. Griep RH, Chor D, Faerstein E, Werneck GL, Lopes CS [Construct validity of the Medical Outcomes Study's social support scale adapted to Portuguese in the Pro-Saude Study]. Cad Saúde Pública. 2005;21(3):703-14. Portuguese. https://doi.org/10.1590/S0102-311X2005000300004 PMID:15868028

19. Forouzan AS, Shushtari JZ, Sajjadi H, Salimi Y, Dejman M. Social Support network among people living with HIV/AIDS in Iran. AIDS Res Treat. 2013;2013:ID715381. https://doi.org/10.1155/2013/715381

20. Aboim S, Vasconcelos P, Wall K. Support, social networks and the family in Portugal: two decades of research. Int Rev Sociol. 2013;23(1):47-67. https://doi.org/10.1080/03906701.2013.771050

21. Wakefield JR, Bickley S, Sani F. The effects of identification with a support group on the mental health of people with multiple sclerosis. J Psychosom Res. 2013;74(5):420-6. https://doi.org/10.1016/j.jpsychores.2013.02.002

22. Guilcher SJ, Casciaro T, Lemieux-Charles L, Craven C, McColl MA, Jaglal SB. Social networks and secondary health conditions: the critical secondary team for individuals with spinal cord injury.J Spinal Cord Med. 2012;35(5):330-42. https://doi.org/10.1179/2045772312Y.0000000035

23. Soares A, Biasoli I, Scheliga A, Baptista RL, Brabo EP, Morais JC et al. Association of social network and social support with healthrelated quality of life and fatigue in long-term survivors of Hodgkin lymphoma. Support Care Cancer. 2013;21(8):2153-9. https://doi.org/10.1007/s00520-013-1775-x

24. Polman $\mathrm{CH}$, Reingold SC, Banwell B, Clanet M, Cohen JA, Filippi M et al. Diagnostic criteria for multiple sclerosis: 2010 revisions to the McDonald criteria. Ann Neurol. 2011;69(2):292-302. https://doi.org/10.1002/ana.22366

25. Kurtzke JF. Rating neurologic impairment in multiple sclerosis: an expanded disability status scale (EDSS). Neurology. 1983;33(11):1444-52. https://doi.org/10.1212/WNL.33.11.1444

26. Sherbourne CD, Stewart AL. The MOS social support survey. Soc Sci Med. 1991;32(6):705-14. https://doi.org/10.1016/0277-9536(91)90150-B

27. Ferreira PL. [Development of the Portuguese version of MOS SF-36. Part II:Validation tests]. Acta Med Port. 2000;13(3):119-27. Portuguese.

28. McKeown LP, Porter-Armstrong AP, Baxter GD. Caregivers of people with multiple sclerosis: experiences of support. Mult Scler. 2004;10(2):219-30. https://doi.org/10.1191/1352458504ms1008oa

29. Hlebec V, Mrzel M, Kogovsek T. Social support network and received suport at stressful events. Metodoloski zvezki. 2009;6(2):155-71. 